\title{
The Effects of Vestibular Rehabilitation after Bilateral Superior Semicircular Canal Dehiscence: A Case Report
}

\author{
Connor L. Naccarato ${ }^{1,2,3}$, Kristen M. Johnson ${ }^{1}$ \\ ${ }^{1}$ University of St. Augustine for Health Sciences, San Marcos, CA, USA \\ ${ }^{2}$ Physio Strength LLC, Tacoma, WA, USA \\ ${ }^{3}$ Bench Mark Rehab Partners, Ooltewah, TN, USA \\ Email: cnaccarato25@gmail.com,kjohnson@usa.edu
}

How to cite this paper: Naccarato, C.L. and Johnson, K.M. (2017) The Effects of Vestibular Rehabilitation after Bilateral Superior Semicircular Canal Dehiscence: A Case Report. International Journal of Clinical Medicine, 8, 439-461.

https://doi.org/10.4236/ijcm.2017.86042

Received: April 17, 2017

Accepted: June 25, 2017

Published: June 28, 2017

Copyright $\odot 2017$ by authors and Scientific Research Publishing Inc. This work is licensed under the Creative Commons Attribution International License (CC BY 4.0).

http://creativecommons.org/licenses/by/4.0/

\begin{abstract}
Background and Purpose: Despite the strong body of evidence for vestibular rehabilitation, research is lacking for effective clinical management of patients with superior semicircular canal dehiscence (SSCD) and endolymphatic hydrops (EH). The purpose of this case report is to describe the effects of physical therapy in the treatment of a patient diagnosed with bilateral SSCD. Case Description: The patient was a 56-year-old woman with a long-standing otologic history involving bilateral SSCD and EH. The patient's body structure and function impairments include constant headaches, dizziness with head rotation and eye movements, sensitivity to sounds and lights, and instability during gait. Her activity limitations include lower extremity dressing, driving, and playing her flute. Her participation restrictions include taking part in social gatherings, going to church, driving longer than 30 minutes, playing with her dogs, and teaching flute lessons. Interventions: Specific interventions included vestibular habituation and adaptation exercises, balance and gait training, and patient education. Physical therapy services were provided for approximately 11 weeks with a frequency of two times per week. Outcomes: After eleven weeks of physical therapy, the patient made improvements on the Lower Extremity Functional Scale (43/80 to 52/80), the Dynamic Gait Index (19/24 to 24/24), the Dizziness Handicap Inventory (86/100 to $68 / 100)$, and the Sharpened Romberg ( 2 seconds to $>30$ seconds). The patient improved in all her activity limitations and participation restrictions. She was able to play her flute for 20-minute intervals, play with her dogs, partake in social gatherings, and drive for 5 hours without symptoms. The patient had plans to pursue surgical intervention within the next year. Discussion: For a patient with a complex otologic history and a current diagnosis of bilateral SSCD, vestibular rehabilitation was an effective management option. The information from this case can be used to guide the effective treatment of similar patients diag-
\end{abstract}


nosed with vestibular dysfunction.

\section{Keywords}

Physical Therapy, Superior Semicircular Canal Dehiscence, Vestibular Rehabilitation, Gaze Stabilization

\section{Introduction}

\subsection{Pathophysiology}

Pathology or dysfunction of the vestibular system can lead to impairments of balance and overall postural control. There are numerous vestibular conditions, many of which are treatable with vestibular rehabilitation. This case report will provide insight on the conservative management of a particular vestibular pathology known as superior semicircular canal dehiscence (SSCD). SSCD is a relatively new condition, first described in 1998 by Minor et al. [1]. To understand the pathophysiology of SSCD, it is important to first review the anatomy of the inner ear and vestibular system. The semicircular canals are filled with a fluid called endolymph which has hair cells embedded within. In normal vestibular sensation, head rotation causes the hair cells in the cupula to bend. Mechanical motion of the cupula is detected by the sensory organ of the canals called the crista ampullaris and transmitted through the vestibular nerve (CNXIII) to the vestibular nuclei located in the brainstem [2]. The central pathways of the vestibular nuclei will not be discussed in detail in this case report. SSCD occurs when there is an opening at the apical turn of the superior SSC, which is thought to alter internal fluid mechanics and disrupt the normal firing rate of the vestibular nerve [2]. This opening in the superior canal creates what was described by Minor et al. as a "mobile third window," in addition to the oval and round windows [1]. In normal inner ear systems, sound waves elicit movement of the stapes, which causes pressure to move through the basilar membrane of the scala tympani and out through the round window to be transmitted through the vestibular nerve and interpreted as sound [2]. In the presence of SSCE, the mobile third window allows for a shunt of acoustic energy. The energy can escape through the third window, causing movement of the cupula, which is then interpreted as a false sense of rotation leading to dizziness or feelings of unsteadiness in the patient [2].

\subsection{Symptoms}

Symptoms of SSCD are not always consistent between patients, and some patients experience bizarre symptoms that are not yet understood or explained pathoanatomically [3]. The most commonly noted symptoms in patients with SSCD are vertigo, oscillopsia, imbalance, hearing loss, and disequilibrium [1] [2]. Smaller dehiscence's $(<2.5 \mathrm{~mm})$ often present with either cochlear or vestibular symptoms, whereas larger dehiscence's $(>2.5 \mathrm{~mm})$ often present with a 
combination of both cochlear and vestibular symptoms but this is not always the case [4]. The most common symptoms of SSCD are Tullio's phenomenon (nystagmus induced by loud noises) and Hennebert's sign (nystagmus induced by excessive pressure in the auditory canal) [2]. It is the disruption of perilymph and endolymph dynamics that makes the vestibular apparatus increasingly sensitive to auditory and pressure stimuli [2]. It is therefore imperative for the clinician to inquire about symptoms being brought on by noises [1]. Often the clinician will notice vertical-torsional eye movements induced by pressure to the inner ear or sound waves. However, without the use of Frenzel lenses, this sign of SSCD could be missed. Often, but not always, patients with SSCD will exhibit vertical-torsional eye movements the plane of the SSC when exposed to sound and pressure stimuli such as Valsalva maneuver [3]. These evoked eye movements are considered to be highly specific for SSCD. Patients with SSCD will often report strange perceptions such as getting dizzy from loud noises, being able to hear their footsteps, and even being able to hear their eyes blink [2]. These symptoms arise from a decrease in sensitivity of air conducted sounds and an increase in sensitivity to bone conducted sounds (especially at low frequencies), resulting in an air-bone gap. The air-bone gap creates a hypersensitivity to acoustics and explains why patients often report hearing their footsteps or heartbeats. The air-bone gap is also the explanation for why many patients with SSCD experience hearing loss at certain sound frequencies. The presence of these bizarre symptoms often causes patients to be mistaken for having a psychiatric condition and may lead to extensive psychiatric interventions and even unwarranted surgeries [2]. Despite the variability in symptoms, most patients end up seeking treatment due to chronic disequilibrium and unsteadiness.

\subsection{A Review of the Literature on Etiology and Prevalence of SSCD}

Due to a relatively new understanding of SSCD, there is not a well-established prevalence of the disorder. One dissection study proposed that the prevalence in the general population is around $0.5 \%$ with most cases occurring on the left side and a higher prevalence in males over females [2]. Another study analyzed 1000 adult temporal bone specimens to determine the incidence of SSCD and found dehiscence in only $0.5 \%$ of the specimens [5]. These researchers also noted that when dehiscence was present, it was often bilateral. It has been suggested that SSCD is due to failure of proper ossification in post-natal bone development, but etiology is poorly understood at this time [5]. It is estimated that in $2.5 \%$ of the population, the bones in the skull only develop to $60 \%-70 \%$ of what is considered full thickness, which could explain a congenital predisposition to SSCD [6]. However, in normal human development, the superior canal is the first canal to ossify, which does not support the theory that SSCD is due to poor ossification in development [2]. In the absence of a congenital deformity, there is no known cause for the erosion of the superior semicircular canal bone, but physical trauma to the skull can play a role [6]. The exact mechanism of SSCD etiolo- 
gy and predisposing factors are unclear as to whether or not it is a congenital or developed condition.

\subsection{Diagnosis}

Due to the high variability in patient reported symptoms, SSCD is often a difficult diagnosis to reach. Many patients are misdiagnosed with other vestibular conditions such as Meniere's disease, perilymph fistula, migraine, otosclerosis and patulous Eustachian tube [1] [3] [7] [8]. The accurate diagnosis of SSCD is dependent on a skilled interpretation of the patient's history, physical examination, and imaging results. Currently, the most reliable way to differentially diagnose SSCD from other inner ear conditions is through a high definition coronal plane computed tomography (CT) scan of the temporal bone [6]. CT scanning is the gold standard to detect the dehiscence of the superior canal and has been shown to have a specificity of $99 \%$ and a positive predictive value of $93 \%$ in the detection of symptomatic SSCD [2]. However, SSCD is detected in about $10 \%$ of all temporal bone CT scans which does not correlate to the $0.5 \%$ prevalence of SSCD in the population and may result in false positives. This discrepancy is explained by the technical issues associated with certain cuts of imaging. It is important to use clinical data in addition to CT scan when diagnosing SSCD in order to reduce the number of false positives [2]. MRI can also be used as a diagnostic tool but is rather expensive and not always deemed necessary in the diagnosis of SSCD. It has been shown to have $96 \%$ sensitivity and $98 \%$ specificity in detecting SSCD but is not always warranted [2]. Other vestibular testing such as vestibular evoked myogenic potential, electrocochleography, and the rotational chair test can also provide valuable information in the differential diagnosis process [6].

\subsection{Surgical Management}

Surgical plugging of the area of dehiscence is a valid option for patients with debilitating symptoms. The bone can be plugged with a bone graft from the temporal bone or cortical bone from the mastoid [2]. Surgical repair of SSCD via a middle fossa approach has been shown to resolve symptoms in $90 \%$ of patients but the bone used to repair the dehiscence can get reabsorbed [6]. There are also complications associated with the middle fossa approach including facial paralysis, cerebrospinal fluid leak, seizures, epidural hematoma, and intracranial bleeding [4]. Using cortical bone from the mastoid is the preferred surgical method because it is less likely to get reabsorbed [2]. Transcanal round window obliteration is another (less invasive) surgical intervention for SSCD that has been highly successful in short-term reduction of symptoms, but there is lacking research regarding the long-term effectiveness of this technique [4]. Given the fact that these surgeries are performed near sensitive, life-sustaining structures, it is crucial to differentially diagnose SSCD and be sure of the diagnosis before surgical intervention [8]. With that said, patients with severe, symptomatic SSCD can benefit from surgical intervention. There is limited research of patients with 
SSCD who choose to decline surgery. However, one study concluded that most patients diagnosed with SSCD who declined surgery did not experience symptoms of hyperacusis, oscillopsia, or autophony. Based on that finding, the presence of autophony in persons with SSCD may warrant the decision to pursue surgery because of its effect on quality of life. Other symptoms that were apparent in almost all patients who chose surgical intervention include pressure induced vertigo, and hyperacusis in response to a tuning fork applied to the extremities [4]. Regardless of the patient's desire to pursue surgical intervention, all patients must be made aware of before electing for surgical intervention.

\subsection{Conservative Management}

Conservative management for SSCD is not well reported in the available vestibular rehabilitation literature to date. However, there is strong evidence supporting the use of vestibular rehabilitation therapy in the presence of vestibular hypofunction. When implemented appropriately, vestibular therapy can help the central nervous system adapt to a dysfunctional vestibular system and correct overdependence on the other two sensory systems (vision and proprioception) [9]. Correcting this imbalance can improve gait stability, reduce anxiety due to spatial disorientation, and address patients' activity limitations and participation restrictions [9]. The following case description will describe a patient with SSCD who attended an outpatient physical therapy clinic and was treated conservatively using vestibular rehabilitation therapy. All interventions used in this case are supported by previous literature to positively influence the vestibular system and will be discussed in further detail in the plan of care. Specific interventions used in this case include patient education, gaze stabilization exercises, environmental modification, sensory re-weighting exercises, perturbations, and core muscle activation [10] [11] [12] [13] [14]. The patient's progress in physical therapy was measured using valid and reliable outcome measures that accurately captured her impairments, activity limitations, and participation restrictions. These outcome measures will be thoroughly explained in the case description [15]-[25].

\subsection{Purpose}

The purpose of this case report is to describe the effects of physical therapy involving vestibular rehabilitation exercises such as gaze stabilization, sensory reweighting, adaptation, and proprioceptive training in the treatment of a patient diagnosed with bilateral SSCD.

\section{Case Description}

\subsection{Subjective}

Informed consent was obtained from the patient to report her case. The patient is a 56-year-old woman with a complex otologic history and bilateral superior semicircular canal dehiscence. Her symptoms first appeared in 1990 with an insidious onset. After no successful diagnosis with over 30 different physician con- 
sults, she finally met with a specialist in otology in 2010 and underwent a middle fossa approach to resurface her right superior semicircular canal. Initially, the patient experienced success from this procedure with a decrease in subjective report of symptoms. However, within the next three years, she subsequently developed reoccurrence of her symptoms due to the bone being resorbed. In 2014 she underwent a trans-mastoid plugging of her right superior semicircular canal which eliminated her symptom of hearing her heartbeat in that ear. After that surgery, she developed an onset of migraine headaches that she describes as present during all waking hours of each day. Despite her surgeries, she continues to experience an increase in her dizziness and headaches with exposure to bright lighting and loud noises, particularly low-frequency sounds. Driving, eye movements, and bending down to tie her shoes or play with her dogs also trigger her dizziness. She experiences autophony in her right ear and perceives an echo of her voice when she speaks as well as a sensation of hearing each footstep inside her right ear. Additionally, she is able to hear her eyes blink and the movement of her temporomandibular joints. When a $256 \mathrm{~Hz}$ tuning fork is applied to her extremities, she reports the vibration deep within her right ear. She experiences constant dizziness and gravitational receptor dysfunction vertigo, which explains her report of often feeling as if she is on a boat. She also experiences sound-induced dizziness (Tullio phenomenon) and spatial disorientation, especially while in social situations with multiple sensory stimuli. When lying supine, she experiences a feeling of increased pressure in her right ear. She has constant tinnitus in her right ear. The patient's stated goals are to return to her job as a professional flute player and flute lesson instructor, be able to drive up to 6 hours, be able to bend down to put shoes on, and be able to go out into social situations all without symptoms.

Other past medical history includes mitral valve prolapse, pulmonary embolism, systemic sclerosis, and tachycardia. Additional past surgical history includes in implanted Greenfield vena cava filter. The patient's current list of medication includes Acetaminophen, Bisoprolol, Celebrex, Cyclobenzaprine, Gabapentin, Hydroxychloroquine, Loratadine, Nifedical, Nortriptyline, Omeprazole, Sertraline, Topiramate, and Tramadol.

\subsection{Medical Testing}

The patient has been referred to physical therapy for vestibular rehabilitation with a medical diagnosis of bilateral superior semicircular canal dehiscence and endolymphatic hydrops. Although her symptoms are primarily on the right side, a bilateral diagnosis was made due to evidence of bilateral dehiscence on imaging. Prior to her physical therapy evaluation she has undergone extensive vestibular testing for the following differential diagnoses: Meniere's disease, benign paroxysmal positional vertigo, vestibular neuritis, vestibular migraine, perilymph fistula, labyrinthine fistula, multiple sclerosis, multisensory dizziness, psychophysiological dizziness, Mal de Debarquement syndrome, labyrinthitis, ototoxicity, cervical vertigo, endolymphatic hydrops, delayed endolymphatic hydrops, laby- 
rinthine concussion, vertebral basilar insufficiency, otosyphilis, presbystasis, mitochondrial myopathy, cardiac arrhythmia, and Arnold-Chiari malformation. Her high-resolution temporal bone CT scan showed superior canal dehiscence on the right, and her MRI showed superior semicircular canal dehiscence on the left as well. Her electrocochleography was positive for endolymphatic hydrops. Her moving Platform Pressure Test was positive in her left ear, which is consistent with SSCD. Her computerized dynamic posturography testing showed evidence of a vestibular deficit type of impaired postural control and increased sway, which is the reason for her referral to physical therapy.

\subsection{Systems Review}

Following the subjective portion of the examination, a thorough physical therapy systems review and screening process was completed as follows:

- Integumentary: WNL-Skin appeared grossly normal, no abnormalities noted.

- Cardiovascular: WNL-HR, BP, radial pulse.

- Musculoskeletal:

o Cervical range of motion (ROM) and shoulder ROM both WNL.

o Standing/seated posture appeared grossly normal, no significant deviations noted.

o The patient demonstrated a dysfunctional gait pattern with non-rhythmic cadence, variable step length, with a tendency to favor her left side and drift toward the left during gait.

- Respiratory: WNL-visible recruitment of accessory breathing muscles.

- Neurological:

o All cranial nerves intact.

o Positive for blurred vision.

o Balance screen indicated possible dysfunction of somatosensory system as patient was unable to perform single leg stance without support. Patient appeared to be heavily reliant on vision and demonstrated moderate sway in normal stance with eyes closed, requiring external support.

Following systems review and screen, the patient was deemed appropriate for further physical therapy testing.

\subsection{Bedside Clinical Ocular Exam}

All vestibular testing was performed with the naked eye as the physical therapist did not have access to Frenzel lenses. Head thrust test was negative indicating intact VOR. Gaze-evoked nystagmus testing was negative. Dix Hallpike test and supine roll test were both negative bilaterally, ruling out BPPV. Interestingly, none of the patient's symptoms were reproduced on the initial evaluation day with any of the vestibular testing. Despite an inability to reproduce symptoms with vestibular testing, further investigation was performed using specific outcome measures to gather objective data.

\subsection{Outcome Measures}

Specific outcome measures were chosen by the physical therapist to best capture 
the patient's impairments, activity limitations, and participation restrictions (Table 1). These outcome measures were also used throughout the course of treatment to monitor the patient's response to treatment objectively.

- Dizziness Handicap Inventory (DHI): This test is a set of questioned specifically aimed at gathering data regarding how the patient's dizziness affects their overall quality of life and difficulty with certain activities. With regards to construct validity of DHI in vestibular dysfunction, there was an adequate relationship between the number of dizzy spells per year and the DHI score [15]. These researchers also found that those patients who reported more frequent attacks of dizziness and unsteadiness scored significantly poorer on DHI, demonstrating content validity [15]. Criterion validity of the DHI was found to have an excellent correlation with the Activities Balance Scale $(\mathrm{ABC})(\mathrm{r}=-0.64)$ and the SF-36 $(\mathrm{r}=0.53$ to $0.72, \mathrm{p}=0.001)$ [16] [17]. The test-retest reliability of DHI total score for vestibular dysfunction was found to be excellent $(r=0.97, p<0.0001)$ [15]. The minimal clinically important difference (MCID) of the DHI specifically for vestibular patients is a decrease of at least 18 points from pre-test to post-test [15].

- Dynamic Gait Index (DGI): This test assesses the patient's ability to change speed and direction, and navigate obstacles during gait. It also stresses the vestibular system by asking the patient to perform various head motions during gait. The DGI has a moderate correlation with the Berg Balance Scale (BERG) for patients with vestibular disorders $(r=0.71 ; p<01)$ which establishes its criterion/concurrent validity [18]. The DGI is more sensitive than the BERG in identifying vestibular patients who are at risk of falling [18]. Test-retest reliability of the DGI total score for vestibular patients has been shown to be excellent (ICC $=0.86$ ) [19]. Interrater reliability of individual DGI items varied from poor to excellent based on kappa values (kappa range, 0.35 - 1.00) [20]. Composite kappa values showed good overall interrater reliability (kappa $=0.64)$ of total DGI scores. The Spearman rho demonstrated excellent correlation $(r=0.95)$ between total DGI scores given concurrently by two different raters [20]. To the author's knowledge, there have not been any studies determining the construct validity of the DGI with vestibular disorders. However, the DGI has been validated for its ability to determine

Table 1. Initial functional status.

\begin{tabular}{cc}
\hline Outcome Measure & Status at Initial Evaluation \\
\hline Lower Extremity Functional Scale & $43 / 80$ \\
Dynamic Gait Index & $19 / 24$ \\
Dizziness Handicap Inventory & $86 / 100$ \\
Sharpened Romberg & 2 Seconds \\
\hline Patient Reported Functional Limitations & Status at Initial Evaluation \\
\hline Playing Flute & Unable to Perform \\
Lower Extremity (LE) Dressing & Severe Limitation, Falls \\
Driving & $<30$ Minutes \\
Stairs & Needs Railing, Head down \\
\hline
\end{tabular}


fallers versus non-fallers in patients with Parkinson's disease and multiple sclerosis [21]. When using the DGI for vestibular patients, the minimal detectable change (MDC) is calculated to be a change of 3.2 points [19] [22].

- Sharpened Romberg: This test involves having the patient stand in tandem stance first with eyes open and then with eyes closed, for a total of 30 seconds each. The Sharpened Romberg has been suggested as a simple test to assess postural control in patients with vestibular hypofunction [9]. The test-retest reliability of the Sharpened Romberg was found to be good at 0.90 - 0.91 eyes open and $0.76-0.77$ eyes closed in healthy women [23]. However, with regards to construct validity, no correlation was found between the Sharpened Romberg and the ABC [24]. The MDC and MCID of the Sharpened Romberg have yet to be established.

- Lower Extremity Functional Scale (LEFS): This test is a questionnaire assessing the patient's difficulty with various activities of daily living. It is not often used for vestibular patients but was used in this case to capture how the patient's condition affected her ability to perform different activities. The construct validity of the LEFS has been shown to be excellent when compared to the physical function portion of the SF-36 $(r=0.80 ; 95 \%)$ [25]. The test-retest reliability of the LEFS has also been shown to be excellent $(r=0.86 ; 95 \%)$ [25]. The MDC and MCID of the LEFS are changes of at least 9 points [25].

\section{Patient Evaluation}

The patient's primary impairments associated with her vestibular condition are dizziness, autophony, acoustic hypersensitivity, Tullio phenomenon, pressure induced vertigo, and postural disequilibrium. The only secondary impairment determined at initial evaluation was the patient's decreased coordination, noted by visual observation of the patient performing outcome measures. The impairments mentioned above interfere with sensory systems that are critical for daily function and can lead to activity avoidance, loneliness, and depression [9] [22]. For the patient in this case, her impairments have led to limitations in certain activities and restricted her from participating in things she was previously able to participate in. All of the patient's specific impairments, activity limitations, and participation restrictions have been outlined in the context of the International Classification of Functioning, Disability, and Health (ICF) (Table 2).

\section{Diagnosis}

The patient's physical therapy diagnoses have been established within the ICD10 classification system as follows:

- R26.2 Difficulty walking, not elsewhere classified.

- R27.8 Other lack of coordination.

\section{Plan of Care}

\subsection{Goals}

The patient's stated goals are to eliminate her symptoms and return to her job as 
Table 2. ICF impairments.

\begin{tabular}{cc}
\hline ICF Domain & Patient Status \\
\hline Body structure function impairments & $\begin{array}{c}\text { Constant headaches, dizziness with head rotation } \\
\text { and lateral eye movements, sensitivity to sounds } \\
\text { and lights and instability while walking. } \\
\text { Lower extremity dressing (difficulty } \\
\text { bending down with flexed head), driving, } \\
\text { and playing her flute. }\end{array}$ \\
Participation restrictions & $\begin{array}{c}\text { Participating in social gatherings with friends, } \\
\text { going to church, driving to destinations that are } \\
\text { greater than } 30 \text { minutes away, playing with her } \\
\text { dogs, and teaching flute lessons. }\end{array}$ \\
\hline
\end{tabular}

a professional flute player and flute lesson instructor. Physical therapy goals were set using outcome measure data as well as patient-reported functional limitations (Table 3). All goals were initially set for 6 weeks considering expected prognosis of the patient in conjunction with her insurance coverage of physical therapy visits.

\subsection{Prognosis}

Due to the patient's complicated otologic history and complex diagnosis, the physical therapy prognosis for this patient was determined to be fair. Her symptoms were not reproducible with vestibular testing and did not have a consistent pattern. Her medical diagnosis was structural in nature and therefore she was not expected to be completely symptom free upon discharge, but she was expected to make functional gains in the aforementioned functional goals. The patient was motivated to participate in physical therapy in hopes to improve her condition and overall quality of life. The frequency and duration of physical therapy sessions were set at two times per week for six weeks, totaling 12 visits, with plans to re-evaluate progress every 30 days. This frequency of twice per week allowed the therapist to monitor progress, review the home exercise program (HEP), and alter interventions accordingly. A successful vestibular rehabilitation program involves weekly visits to the therapist, in conjunction with daily repetition of exercises by the patient at home [26]. As a patient begins to show a decreased rate of progression, it is common to decrease the frequency of office visits to bi-weekly and emphasize a home maintenance program [26]. In this particular case, the patient was on vacation during week three of treatment and was forced to decrease frequency after week eight to once per week due to financial reasons.

\subsection{Treatment Plan}

The proposed plan of care for this patient addressed the aforementioned body structure/function impairments, activity limitations, and participation restrictions. The treatment consisted heavily of vestibular adaptation exercises, habituation exercises, static and dynamic balance activities, gait training, and patient 
Table 3. Patient goals.

\begin{tabular}{ccc}
\hline Outcome Measure & Initial & Goal \\
\hline Lower Extremity Functional Scale & $43 / 80$ & $55 / 80$ \\
Dynamic Gait Index & $19 / 24$ & $24 / 24$ \\
Dizziness Handicap Inventory & $86 / 100$ & $66 / 100$ \\
Sharpened Romberg & 2 seconds & 30 seconds \\
\hline Patient Reported Functional & Initial & Goal \\
Limitations & Unable to perform & 2x/week for 30 minutes \\
Flute & Severe limitation, falls & Easy, symptom free \\
LE Dressing & $<30$ minutes & 6 hours \\
Driving & Needs railing, head down & No railing, looking ahead \\
\hline Stairs & &
\end{tabular}

education.

Educating the patient about her condition was the priority of the first treatment session. Compliance with physical therapy programs and HEP can be increased by addressing barriers that patients perceive, increasing positive feedback, and reducing perceived helplessness [10]. Helping the patient understand her condition and her role in the physical therapy management process is important to ensure compliance [10].

A conflict between sensory information from the vestibular and visual systems can lead to a disrupted perception of spatial orientation and cause a feeling of disequilibrium [11]. Repetition of vestibular and visual exercises has been shown to cause adaptation of these systems and eliminate symptoms in these patients [11]. One study using X1 and X2 gaze stabilization exercises showed significant improvements in recovery of gaze stability during head movements in patients with bilateral vestibular hypofunction [22]. The patients involved in this study were told to perform the exercises 4 - 5 times daily and demonstrated improvements in about five weeks, indicating that repetition is likely an important consideration in a vestibular adaptation exercise program [22].

Hearing can have an impact on balance as well. Impaired hearing has been shown to increase postural sway suggesting that auditory input is critical for maintaining balance [12]. With that evidence in mind, many of the adaptation exercises used in this case report were first performed in a quiet room and progressively carried out in the busy gym environment of the clinic to maximize external stimuli. Having the patient perform exercises in a therapy gym with different auditory stimuli including music and various voices was a strategy used to mimic other environments the patient will be exposed to throughout her everyday life.

Patients with vestibular system dysfunction tend to rely more heavily on proprioception and vision for maintaining balance and making postural adjustments. This tendency leads to abnormal patterns of dependence on other sensory stimuli and can result in further inhibition of the vestibular system [9]. Sensory reweighting interventions such as balance training are beneficial for 
these patients because they can help restore a more normalized relationship between the three sensory systems involved with balance. One review of the literature concluded that balance training under single-task conditions does not transfer to multiple task situations [13]. This idea further supports the notion of training specificity and implies that successfully improving a person's balance in everyday life situations requires dual task balance training [13]. The balance training used in this case report started with single-task conditions and progressed to dual task balance training as the patient improved.

Perturbation training is effective in training the proprioceptive system to be able to recover balance in response to non-anticipatory stimuli [13]. This type of training utilizes the specificity principle of training and is most similar to real life balance recovery situations because the patient does not have anticipatory control over the situation. Perturbation training has been shown to be superior to traditional balance exercises in improving reactive postural control [13]. Based on the evidence, perturbation training was also utilized in this case report.

Activation of the core musculature is necessary for a person to make postural adjustments. Although there is a debate in the literature as to which exact muscles are considered "the core", it is widely accepted that the core consists of the muscles around the trunk and lumbopelvic region [14]. Performing exercises on a stability ball leads to greater recruitment of core musculature, which can therefore enhance one's ability to make postural adjustments and react to external demands [14]. Based on the balance screen portion of the neurological systems review and the DGI testing, the patient demonstrates difficulty with dynamic postural control. Stability ball training was used in conjunction with perturbation training to maximize the patient's ability to use core musculature in response to external stimuli.

Treatments were progressed based on patient response and it is important to note that there are no specific guidelines with regards to appropriate progression. The patient was advanced to more challenging vestibular adaptation and balance exercises once she was able to successfully complete an exercise for two 30 second intervals, in two consecutive sessions, without symptoms. Intervention progression of vestibular adaptation exercises consisted of increasing speeds and altering the external environment. The initial exercises given have been outlined and described (Table 4). Interventions were performed in the clinic twice per week and also taught to the patient to complete as her home exercise program (HEP). She also received a printout of her HEP with instructions and visual aids. The initial exercises were progressed as the patient tolerance to these activities improved, and new exercises were added as the patient's symptoms decreased (Table 5).

\section{Implementation of Interventions}

An overview of each week of treatment is provided with information about the patient's response to interventions. Symptoms were monitored clinically via subjective report of the patient using a modified version of the Borg category 
Table 4. Initial exercises (weeks 1 - 4).

\begin{tabular}{|c|c|c|}
\hline $\begin{array}{c}\text { Specific } \\
\text { Interventions }\end{array}$ & Description/Progressions & Rationale \\
\hline Patient education & $\begin{array}{l}\text { Education regarding relationship } \\
\text { between visual, vestibular, and } \\
\text { somatosensory systems. }\end{array}$ & $\begin{array}{l}\text { Increase patient } \\
\text { confidence in physical } \\
\text { therapy and } \\
\text { compliance with HEP. }\end{array}$ \\
\hline $\begin{array}{l}\text { VOR oculomotor } \\
\text { exercises }\end{array}$ & $\begin{array}{l}\text { Therapist holds pen out in front of patient } \\
\text { and moves pen horizontally within } \\
\text { 60-degree arc from patient's visual field } \\
\text { while patient tracks pen with only eye } \\
\text { movement. Progressed to vertical and } \\
\text { diagonal patterns and different speeds. }\end{array}$ & $\begin{array}{c}\text { Enhance vestibular } \\
\text { adaptation. }\end{array}$ \\
\hline $\begin{array}{c}\text { VOR X1 gaze } \\
\text { stabilization exercises }\end{array}$ & $\begin{array}{l}\text { Therapist holds pen out in front of patient } \\
\text { while patient fixes eyes on pen and slowly } \\
\text { but continuously rotates head horizontally } \\
\text { 60-degrees to either side. Progressed } \\
\text { to vertical and diagonal patterns } \\
\text { and different speeds. }\end{array}$ & $\begin{array}{l}\text { Encourage dissociation } \\
\text { of eye/head movement. }\end{array}$ \\
\hline $\begin{array}{l}\text { VOR X2 exercises } \\
\text { (eyes/head opposite) }\end{array}$ & $\begin{array}{l}\text { Therapist holds pen out in front of patient } \\
\text { and moves pen horizontally within } \\
\text { 60-degree arc from patient's visual field } \\
\text { while patient tracks pen with eyes and slowly } \\
\text { but continuously rotates head in opposite } \\
\text { direction of pen. Progressed to vertical and } \\
\text { diagonal patterns and different speeds. }\end{array}$ & $\begin{array}{l}\text { Enhance vestibular } \\
\text { adaptation by } \\
\text { improving } \\
\text { optokinetics and } \\
\text { inducing retinal slip. }\end{array}$ \\
\hline $\begin{array}{l}\text { Walking with } \\
\text { horizontal head } \\
\text { turns, eyes fixed } \\
\text { ahead on target }\end{array}$ & $\begin{array}{l}\text { Patient ambulates straight ahead linearly } \\
\text { while slowly and continuously turning head } \\
\text { 30-degrees to either side. Progressed with } \\
\text { various speeds of gait and head turning. }\end{array}$ & $\begin{array}{l}\text { Enhance vestibular } \\
\text { adaptation during } \\
\text { dynamic activity. }\end{array}$ \\
\hline $\begin{array}{l}\text { Walking with vertical } \\
\text { head nods, eyes fixed } \\
\text { ahead on target }\end{array}$ & $\begin{array}{l}\text { Patient ambulates straight ahead linearly } \\
\text { while slowly and continuously nodding head } \\
\text { 30-degrees up and down. Progressed with } \\
\text { various speeds of gait and head movements. }\end{array}$ & $\begin{array}{l}\text { Enhance vestibular } \\
\text { adaptation during } \\
\text { dynamic activity. }\end{array}$ \\
\hline $\begin{array}{l}\text { Walking with eyes } \\
\text { looking left/right }\end{array}$ & $\begin{array}{l}\text { Patient ambulates straight ahead linearly } \\
\text { while moving eyes horizontally. Progressed } \\
\text { with various speeds of gait. }\end{array}$ & $\begin{array}{l}\text { Utilize all sensory } \\
\text { inputs to improve } \\
\text { dynamic postural } \\
\text { control. }\end{array}$ \\
\hline $\begin{array}{l}\text { Walking with eyes } \\
\text { looking up/down }\end{array}$ & $\begin{array}{c}\text { Patient ambulates straight ahead linearly } \\
\text { while moving eyes vertically. Progressed } \\
\text { with various speeds of gait. }\end{array}$ & $\begin{array}{l}\text { Utilize all sensory } \\
\text { inputs to improve } \\
\text { dynamic postural } \\
\text { control. }\end{array}$ \\
\hline $\begin{array}{l}\text { Standing balance } \\
\text { (dynamic surface) }\end{array}$ & $\begin{array}{c}\text { Dynamic surface used was Airex pad. } \\
\text { Progressed to unilateral stance, eyes closed, } \\
\text { perturbations. }\end{array}$ & $\begin{array}{l}\text { Promote increased } \\
\text { utilization of } \\
\text { somatosensory } \\
\text { system in } \\
\text { postural control. }\end{array}$ \\
\hline $\begin{array}{c}\text { Tandem balance } \\
\text { (eyes open) }\end{array}$ & $\begin{array}{l}\text { Standing with feet in tandem stance. } \\
\text { Progressed to Airex pad, eyes } \\
\text { closed, perturbations. }\end{array}$ & $\begin{array}{l}\text { Promote increased } \\
\text { utilization of } \\
\text { somatosensory } \\
\text { system in postural } \\
\text { control by altering } \\
\text { base of support. }\end{array}$ \\
\hline
\end{tabular}


Table 5. Additional interventions (added weeks 4 - 8).

\begin{tabular}{|c|c|c|}
\hline $\begin{array}{c}\text { Specific } \\
\text { Interventions }\end{array}$ & Description/Progressions & Rationale \\
\hline $\begin{array}{l}\text { VOR X1/X2 exercises } \\
\text { with walking }\end{array}$ & $\begin{array}{l}\text { Same X1/X2 exercises described previously } \\
\text { but now performed during forward } \\
\text { ambulation with the patient holding } \\
\text { the pen. Progressed with duration, } \\
\text { speed of gait and head turns. }\end{array}$ & $\begin{array}{l}\text { Mimic functional } \\
\text { everyday tasks and } \\
\text { promote safe } \\
\text { vestibular adaptation. }\end{array}$ \\
\hline $\begin{array}{l}\text { VOR X1/X2 exercises } \\
\text { with side-stepping }\end{array}$ & $\begin{array}{l}\text { Same X1/X2 exercises described previously } \\
\text { but now performed while side-stepping in } \\
\text { frontal plane with patient holding the pen. } \\
\text { Progressed with duration, speed of gait and } \\
\text { head turns. }\end{array}$ & $\begin{array}{l}\text { Challenge vestibular } \\
\text { system and promote } \\
\text { vestibular adaption } \\
\text { through functional } \\
\text { movement. }\end{array}$ \\
\hline Stool push & $\begin{array}{l}\text { With patient seated on stool, therapist } \\
\text { pushes patient (forward translation) while } \\
\text { patient performed head turns in various } \\
\text { directions. Progressed with speed of head } \\
\text { turns and speed of linear translation. }\end{array}$ & $\begin{array}{l}\text { Mimic functional } \\
\text { driving scenario } \\
\text { and enhance } \\
\text { vestibular adaptation. }\end{array}$ \\
\hline $\begin{array}{l}\text { Stability ball arm } \\
\text { reaches }\end{array}$ & $\begin{array}{l}\text { Patient seated on stability ball and reaches } \\
\text { arms in various directions with trunk } \\
\text { excursion. Progressed to eyes closed } \\
\text { and perturbations. }\end{array}$ & $\begin{array}{l}\text { Challenge dynamic } \\
\text { stability and encourage } \\
\text { cephalocaudal } \\
\text { functional activity. }\end{array}$ \\
\hline $\begin{array}{l}\text { Stability ball } \\
\text { marching }\end{array}$ & $\begin{array}{l}\text { Patient seated on stability ball alternating } \\
\text { lifting legs from floor. Progressed to } \\
\text { opposite arm/leg, eyes closed, } \\
\text { and perturbations. }\end{array}$ & $\begin{array}{c}\text { Narrow base of support } \\
\text { in order to increase } \\
\text { somatosensory } \\
\text { demands. }\end{array}$ \\
\hline Ladder drills & $\begin{array}{l}\text { Various stepping drills with agility ladder. } \\
\text { Progressed to head turns, different visual } \\
\text { fixation, increased speeds. }\end{array}$ & $\begin{array}{l}\text { Reinforce normalized } \\
\text { movement patterns and } \\
\text { ability for vestibular } \\
\text { system to adapt to } \\
\text { transition in direction } \\
\text { and speed. }\end{array}$ \\
\hline Cone reaches & $\begin{array}{l}\text { Hip hinge on single leg (golfer's lift) } \\
\text { reaching for cones placed near patient's feet. }\end{array}$ & $\begin{array}{l}\text { Mimic functional } \\
\text { reaching task and } \\
\text { promote vestibular } \\
\text { adaptation. }\end{array}$ \\
\hline $\begin{array}{l}\text { Patient education } \\
\text { on playing flute }\end{array}$ & $\begin{array}{l}\text { Patient brought flute into clinic so } \\
\text { therapist could understand demands of } \\
\text { the activity and offer suggestions to } \\
\text { minimize symptoms. }\end{array}$ & $\begin{array}{l}\text { Functional activity of } \\
\text { high importance to } \\
\text { patient. }\end{array}$ \\
\hline
\end{tabular}

scale [27]. The Borg category scale is often used to assess patients' rating of perceived exertion or perceived dyspnea [27]. It has been shown to have high concurrent validity when compared to the modified Medical Research Council scale ( $r s=0.79)$, the Oxygen-Cost Diagram ( $r s=-0.83$ ), and the Baseline Dyspnea Index ( $\mathrm{rs}=-0.71$ ) [27]. In the context of this case report, a modified Borg rating scale for dizziness was used, which asks the patient to rate their perceived dizziness from 0 (nothing at all) to 10 (maximal) [28]. When performing exercises in the clinic and during the HEP, the patient was instructed to keep her symptoms less than a 4/10 and discontinue the activity if her symptoms reached a 5/10 on 
the modified Borg rating scale for dizziness.

Week 1: The first week of treatment consisted of VOR X1 and X2 exercises to challenge the vestibular system. The patient first performed all of these activities in the seated position. All X1 and X2 patterns were performed for 30 seconds or until her symptom of headache or dizziness exceeded $4 / 10$ on the modified Borg rating scale for dizziness. Between each exercise she rested for 10 - 30 seconds or until her symptoms decreased to her baseline (which she reported as $2 / 10$ ). The same 60-degree total arc of motion was used for each pattern. The patient had particular difficulty with the head and eyes moving in opposite directions, especially in the horizontal plane and diagonal planes. Her symptoms came on sooner, and she required increased rest time with these exercises. After her first treatment session, the $\mathrm{X} 1$ and $\mathrm{X} 2$ exercises were progressed to being performed in standing with a narrow base of support (BOS). All exercises during the first week of treatment were performed in private treatment room to minimize sensory stimuli.

Week 2: The second week of treatment involved increasing the speed of all VOR X1 and X2 exercises and further increasing difficulty by altering BOS on a foam pad. New interventions added in week 2 included walking $50 \mathrm{ft}$ while continuously moving the head in all directions (side to side, up and down, and diagonal patterns). She presented with decreased ability to walk in a straight path (often drifting left) and demonstrated variable stride length and occasional stumbles. Her symptoms of dizziness occurred after each exercise and she was given a rest in between for her symptoms to calm down. After completing each direction of head/eye movement once, the patient was instructed to repeat each head motion while focusing eyes on target across the room. She completed these exercises with an increase in dizziness after each, especially the horizontal head movement.

Another intervention added in the second week of treatment was standing on the foam pad with wide BOS and eyes closed. The patient required hand-held assist (HHA) to complete this exercise for 1 minute and demonstrated increased ankle strategies to maintain balance. All interventions during week two and beyond were performed in therapy gym to allow for an increase in sensory stimuli to help mimic real world environment. The treatment gym has auditory stimuli (music and voices) and variable visual stimuli including natural lighting from windows, overhead lighting, and other patients moving about the therapy gym.

Week 3: Patient was absent from physical therapy due to personal vacation. Before leaving, she was instructed to continue with HEP and monitor symptoms. She was also instructed to perform her VOR exercises while on the train with a moving background. After vacation, she reported no symptoms while on the train but she did forget to perform her HEP on the train.

Week 4: During the fourth week of treatment the patient was able to tolerate a further increase in speed and duration of X1 and X2 exercise up to 2 minutes while standing on a foam pad. Her gait pattern with the walking exercise was 
becoming more normalized with symmetrical step length and only occasional drift to her left side. She was able to increase gait speed as well. She was able to tolerate 30 seconds of standing on the foam pad with eyes closed, standby assist (SBA) and only minimal ankle strategies to maintain an upright posture. New interventions added in the fourth week of treatment included side-stepping while performing pen exercises in the horizontal plane. This intervention was added based on the patient's responses to interventions over the past couple weeks. She experienced increased symptoms when pairing a linear movement with head and eye movements in opposite directions.

Week 5: Interventions added during week five treatments included the stool push exercises was used specifically to reproduce the linear translation associated with driving. The therapist instructed the patient to turn head at various points in time while pushing the patient forward on the stool. Initially, the patient had difficulty with turning head due to fear of falling off stool and minor reports of dizziness. She progressed well through this exercise demonstrating improved ability to tolerate horizontal head and eye movements during forward linear translation. Other exercises were progressed appropriately.

Week 6: New interventions added in week six included stair training and seated exercises on a stability ball. The stair training began with allowing the patient to navigate the stairs using a handrail on her preferred side and visual fixation of her choosing. When asked to keep eyes fixed 3 - 4 steps ahead of her rather than straight down at her feet, she demonstrated decreased speed and occasional scuffing of feet on stairs. The Patient was able to navigate stairs without handrail only when compensating with visual fixation on her feet. She eventually progressed to safely navigating stairs without using a handrail. The patient initially demonstrated decreased postural control while performing upper extremity reaching and lower extremity marching exercises on the stability ball. However, by the end of the sixth week, she improved significantly with these activities. She was able to maintain upright posture with minimal trunk sway in response to perturbations. Other exercises were progressed appropriately.

Week 7: During week seven, single leg cone reaches and various drills using the agility ladder were added. Single leg cone reaches were added specifically to improve the patient's ability to reach for things on the ground, an activity that often exacerbated her symptoms. She was instructed to hinge at her hips and reach toward 3 different cones place near her feet. Initially, she demonstrated decreased dynamic postural control with this activity and required HHA. After two sessions of performing this exercise she demonstrated significant improvement in her ability to hinge at her hips and reach down for objects without any onset of symptoms. The agility ladder was used to encourage increased body awareness by using various stepping patterns without allowing patient to fixate her eyes on her feet.

Week 8: No new interventions were added during week 8. The patient continued to show progress with balance activities but still had some difficulty with horizontal head turn while side-stepping. After eight weeks of treatment, the 
primary author had discontinued working at the physical therapy clinic and the remaining three weeks of care was carried out by another physical therapist. Interventions during the final three weeks of treatment remained the same but were adjusted accordingly in regards to volume and intensity based on patient tolerance. The patient was forced to decrease the frequency of physical therapy to once per week during the final three weeks due to financial reasons. The patient was compliant with HEP throughout the entire course of treatment, based on subjective report.

\section{Outcomes}

Every four weeks, progress notes indicating the patient's response to physical therapy treatment were completed. A final discharge note was written after the eleventh week of treatment due to the patient's decision to discontinue physical therapy based on financial reasons. In the context of the ICF framework, the patient demonstrated mild improvement in body structure-function impairments and significant improvements in her activity limitations and participation restrictions as outlined below. Specific objective outcomes based on patient goals from initial evaluation can be found in Table 6 .

Table 6. Patient progress toward goals.

\begin{tabular}{|c|c|c|c|c|c|}
\hline $\begin{array}{l}\text { Outcome } \\
\text { Measure }\end{array}$ & Initial & 4 Weeks & 8 Weeks & 11 Weeks & Status \\
\hline $\begin{array}{c}\text { Lower } \\
\text { Extremity } \\
\text { Functional Scale }\end{array}$ & $43 / 80$ & $38 / 80$ & $52 / 80$ & $58 / 80$ & $100 \% \mathrm{Met}$ \\
\hline $\begin{array}{c}\text { Dynamic Gait } \\
\text { Index }\end{array}$ & $19 / 24$ & $22 / 24$ & $19 / 24$ & $24 / 24$ & $100 \% \mathrm{Met}$ \\
\hline $\begin{array}{l}\text { Dizziness } \\
\text { Handicap } \\
\text { Inventory }\end{array}$ & $86 / 100$ & $74 / 100$ & $74 / 100$ & $68 / 100$ & $90 \%$ Met \\
\hline $\begin{array}{l}\text { Sharpened } \\
\text { Romberg }\end{array}$ & 2 seconds & $\begin{array}{c}>30 \text { seconds } \\
\text { no sway }\end{array}$ & $\begin{array}{c}>30 \text { seconds } \\
\text { no sway }\end{array}$ & $\begin{array}{c}>30 \text { seconds, } \\
\text { no sway }\end{array}$ & $100 \% \mathrm{Met}$ \\
\hline $\begin{array}{c}\text { Patient } \\
\text { Reported } \\
\text { Functional } \\
\text { Limitations }\end{array}$ & Initial & 4 Weeks & 8 Weeks & 11 Weeks & Status \\
\hline Playing Flute & $\begin{array}{l}\text { Unable to } \\
\text { Perform }\end{array}$ & $\begin{array}{c}5-10 \\
\text { minutes }\end{array}$ & $\begin{array}{l}15-30 \\
\text { minutes }\end{array}$ & $\begin{array}{l}\text { Up to } 2 \text { hours, } \\
\text { mild-moderate } \\
\text { symptoms }\end{array}$ & $70 \%$ Met \\
\hline $\begin{array}{c}\text { Lower Extremity } \\
\text { Dressing }\end{array}$ & $\begin{array}{c}\text { Severe } \\
\text { Limitation, falls }\end{array}$ & $\begin{array}{l}\text { Difficult, } \\
\text { needs } \\
\text { support }\end{array}$ & $\begin{array}{l}\text { Needs } \\
\text { support }\end{array}$ & $\begin{array}{c}\text { Less support } \\
\text { required }\end{array}$ & $90 \%$ Met \\
\hline Driving & $<30$ minutes & $\begin{array}{c}30 \\
\text { minutes }\end{array}$ & 1 hour & 45 minutes & $20 \%$ Met \\
\hline Stairs & $\begin{array}{l}1 \text { at a time, } \\
\text { needs railing, } \\
\text { head down }\end{array}$ & $\begin{array}{c}\text { Needs railing, } \\
\text { head down }\end{array}$ & $\begin{array}{l}\text { No railing } \\
\text { ascending, needs } \\
\text { railing down }\end{array}$ & No railing & $80 \%$ Met \\
\hline
\end{tabular}

Note: Normative value for the sharpened Romberg test is $>30$ seconds [9]. 


\subsection{Body Structure Function Impairments}

After eleven weeks of physical therapy treatment, the patient demonstrated a decrease in her frequency and duration of headaches. She continues to experience occasional dizziness with head rotation and lateral eye movement, but she reports that the severity of her symptoms has decreased tremendously. She also continues to experience increased sensitivity to loud noises and bright lights, but she has learned strategies to manage her symptoms. She reports that physical therapy has allowed her to understand the specific triggers for her symptoms and has taught her strategies manage those symptoms better.

\subsection{Activity Limitations}

The patient has learned strategies to complete activities she was previously unable to complete without experiencing symptoms. She is now able to perform LE dressing tasks with only minimal handheld support and no onset of symptoms. Although she is still unable to play her flute without symptoms, she does report her symptoms have lessened as she has learned strategies to minimize symptoms during this activity. She can tolerate playing her flute for up to 2 hours. She can drive a maximum of one hour before experiencing symptoms, but she reports the gaze exercises she learned in physical therapy have helped improve her ability to drive.

\subsection{Participation Restrictions}

The patient made the most notable progress in regards to her participation restrictions. Before starting physical therapy, she was unable to participate in social gatherings or go to church. She is now able to participate in both of those activities and has learned how to prevent and manage her symptoms during. She often keeps earplugs in her purse and finds that wearing them can help decrease her symptoms when they come on in social situations. She is now able to walk and play with her dogs without any onset of symptoms. She is still unable to participate in teaching flute lessons.

\subsection{Subjective Outcomes of Patient}

Overall, the patient reported she was $50 \%$ better as a result of physical therapy interventions. She was overall pleased with her improvement and felt as if she had gained the appropriate knowledge and skills for her to manage her condition successfully upon discontinuation of physical therapy services. She stated that physical therapy has taught her many strategies to understand her body better and manage her symptoms. Despite the improvement made from conservative management of the patient's condition, she continues to experience symptoms that interfered with her quality of life and does plan to seek surgical intervention for her condition in the future from a surgeon specializing in SSCD.

\section{Discussion}

The purpose of this case report is to describe the effects of physical therapy in- 
volving vestibular rehabilitation exercises such as gaze stabilization, sensory reweighting, adaptation, and proprioceptive training in the treatment of a patient diagnosed with bilateral SSCD. With eleven weeks of physical therapy emphasizing vestibular rehabilitation, the patient demonstrated mild improvement in her body structure/function impairments, and significant improvements in her activity limitations, and participation restrictions. The most significant improvements for this patient were in her ability to participate in social gatherings, play with her dogs, and drive with minimal to no symptoms. This case report is one of few pieces of literature describing the effects of physical therapy services on a patient diagnosed with bilateral SSCD.

The initial treatment focused on educating the patient on the pathophysiology of her condition and helping her understand the relationship among the visual, vestibular, and somatosensory systems. This early education allowed for increased patient compliance in the program. The next priority in treatment was to initiate gaze stabilization exercises and sensory reweighting exercises to facilitate vestibular adaptation. The therapist taught all VOR gaze stabilization exercises to the patient so that the patient could complete these as part of her HEP. The patient progressed well through all interventions and demonstrated improvement from session to session.

When treating a patient with SSCD, it is important to understand the treatment options available for that patient. A thorough understanding of the surgical approaches available, as well as the success rates and associated risks with each procedure is crucial. There is a limited research of patients with SSCD who choose to decline surgery. However, one study concluded that most patients diagnosed with SSCD who declined surgery did not experience symptoms of hyperacusis, oscillopsia, or autophony [4]. The presence of autophony in persons with SSCD may warrant the decision to pursue surgery because of its effect on quality of life. Other symptoms that were apparent in almost all patients who chose surgical intervention include pressure induced vertigo, and hyperacusis in response to a tuning fork applied to the extremities [4]. This information is important to share with patients who inquire about surgical intervention.

Because balance and posture are critical functions of human life, patients with vestibular dysfunction are more likely to experience psychological distress such as anxiety, depression, withdrawal, avoidance, and loneliness [9]. In this particular case, the patient did report that her quality of life was affected but did not show any signs of depression. Although her social life was limited, she appeared happy and reported that she was still able to maintain positive relationships with her family and friends. When working with any vestibular patient, it is important for clinicians to inquire about their overall quality of life and be aware of this phenomenon to know when to refer patients to the appropriate resources.

The amount of variation in treatment interventions is a primary limitation of this case report. With a physical therapy approach that involves interventions targeting multiple bodily systems, it is difficult to determine which interventions were most effective. Another limitation of this case report is the fact that treat- 
ment was interrupted by the patient's personal vacation. A lapse in physical therapy management may have hindered the progress of the patient. A third limitation of this case report was the patient's availability of financial resources. After she had completed her first twelve visits, her insurance no longer covered physical therapy treatment and she was forced to pay cash, which further limited her attendance. Lastly, the patient was obliged to drive herself to physical therapy appointments, which is one of the activities that exacerbated her symptoms. Often, her ability to complete all interventions was limited by an increased baseline of symptoms from driving to the clinic.

There are possible alternative explanations for the patient's decrease in symptoms and improvements in functional mobility. The improvements made by this patient could be attributed to factors other than the physical therapy interventions such as time, social interaction, or the effects of neuroplasticity. Another factor that may have contributed the patient's overall improvement is the dandelion root tea she drank daily. Dandelion root extract has been shown to act as a diuretic, serve as an antioxidant, and decrease inflammation [29] [30]. The diuretic effects of the dandelion root tea may have contributed to normalizing the pressure balance of endolymph and perilymph in the semicircular canals, but more research needs to be conducted to support this hypothesis [29] [30]. In retrospect, this case could be improved by limiting treatment variables to determine which intervention was most effective.

A possible explanation for the patient's decreased score on the DGI and DHI at the eight-week interval is that she was participating in more activities than she previously was which may have caused her to be more aware of her limitations. As her symptoms decreased, she was more active in social situations, which may have informed her of new activity limitations that she was previously unaware of because she had not attempted them. Other outcome measures could have been added to the plan of care to better identify the patient's progress with sensory reweighting. A recommended outcome measure to use in further studies of patients with SSCD is the Clinical Test of Sensory Interaction and Balance (CTSIB) because of its ability assess balance in a variety of conditions. The CTSIB allows the tester to infer which sensory systems are most dysfunctional based on the patient's ability to tolerate each condition [31].

Although successful conservative management for SSCD is not well established in the literature, this case report provides evidence to support the effectiveness of gaze stabilization and sensory re-weighting exercises in the clinical management of patients with SSCD. The current clinical practice guidelines for vestibular hypofunction suggest that a supervised vestibular rehabilitation program can improve patient outcomes, quality of life, and psychological well-being [32]. The treatment program outlined in this case report can be practically applied in a clinical setting. Physical therapists and other healthcare professionals can use these gaze stabilization and sensory re-weighting exercises with their patients to help improve function and restore any activity and participation restrictions. 
Successful results of vestibular rehabilitation in the treatment of vestibular hypofunction are well supported in the literature [9] [22] [32]. However, more research is warranted to determine confidently the specific interventions that produce positive outcomes in patients diagnosed with SSCD. Further research should also be conducted to identify certain patient characteristics that may provide insight as to which patients will respond best to conservative management of SSCD and which patients should consider surgical intervention. A successful physical therapy treatment program for SSCD should consider all patient impairments, activity limitations, and participation restrictions. The results of this case cannot be generalized to all patients with vestibular hypofunction, but it does provide a viable treatment protocol for patients diagnosed with unilateral or bilateral SSCD. All patients seeking physical therapy management should be thoroughly evaluated and treated via an individualized physical therapy program tailored to individual impairments.

\section{References}

[1] Minor, L.B., Solomon, D., Zinreich, J. and Zee, D.S. (1998) Sound- and/or Pressure-Induced Vertigo Due to Bone Dehiscence of the Superior Semicircular Canal. Archives of Otolaryngology_Head and Neck Surgery, 124, 249-258. https://doi.org/10.1001/archotol.124.3.249

[2] Hagr, A. (2010) Superior Canal Dehiscence Syndrome. Journal of King Saud University, 17, 57-72. https://doi.org/10.4197/med.17-2.5

[3] Belden, C.J., Weg, N., Minor, L.B. and Zinreich, S.J. (2003) CT Evaluation of Bone Dehiscence of the Superior Semicircular Canal as a Cause of Sound- and/or Pressure-Induced Vertigo. Radiology, 226, 337-343. https://doi.org/10.1148/radiol.2262010897

[4] Benamira, L.Z., Maniakas, A., Alzahrani, M. and Salibaa, I. (2015) Common Features in Patients with Superior Canal Dehiscence Declining Surgical Treatment. Journal of Clinical Medicine Research, 7, 308-314. https://doi.org/10.14740/jocmr2105w

[5] Carey, J.P., Minor, L.B. and Nager, G.T. (2000) Dehiscence or Thinning of Bone Overlying the Superior Semicircular Canal in a Temporal Bone Survey. Archives of Otolaryngology-Head and Neck Surgery, 126, 137-147. https://doi.org/10.1001/archotol.126.2.137

[6] Asal, S. (2013) Atypical Superior Semicircular Canal Dehiscence Case Report. The Egyptian Journal of Otolaryngology, 29, 209-215.

[7] Halmagyi, G.M., Aw, S.T., McGarvie, L.A., et al. (2003) Superior Semicircular Canal Dehiscence Simulating Otosclerosis. The Journal of Laryngology \& Otology, 117, 553-557. https://doi.org/10.1258/002221503322113003

[8] Li, P.M., Bergeron, C., Monfared, A., Agrawal, S. and Blevins, N.H. (2011) Superior Semicircular Canal Dehiscence Diagnosed after failed Stapedotomy for Conductive Hearing Loss. American Journal of Otolaryngology, 32, 441-444. https://doi.org/10.1016/j.amjoto.2010.07.016

[9] Black, F.O. and Pesznecker, S.C. (2003) Vestibular Adaptation and Rehabilitation. Current Opinion in Otolaryngology \& Head and Neck Surgery, 11, 355-360. https://doi.org/10.1097/00020840-200310000-00008

[10] Sluijs, E.M., Kok, G.J. and van der Zee, J. (1993) Correlates of Exercise Compliance 
in Physical Therapy. Physical Therapy, 73, 771-782.

https://doi.org/10.1093/ptj/73.11.771

[11] Rine, R.M., Schubert, M.C. and Balkany, T.J. (1999) Visual-Vestibular habituaTion and Balance Training for Motion Sickness. Physical Therapy, 79, 949-957.

[12] Kanegaonkar, R.G., Amin, K. and Clarke, M. (2012) The Contribution of Hearing to Normal Balance. The Journal of Laryngology \& Otology, 126, 984-988. https://doi.org/10.1017/S002221511200179X

[13] Granacher, U., Muehlbauer, T., Zahner, L., Gollhofer, A. and Kressig, R.W. (2011) Comparison of Traditional and Recent Approaches in the Promotion of Balance and Strength in Older Adults. Sports Medicine, 41, 377-400. https://doi.org/10.2165/11539920-000000000-00000

[14] Marshall, P.W. and Murphy, B.A. (2005) Core Stability Exercises on and off a Swiss Ball. Archives of Physical Medicine and Rehabilitation, 86, 242-249. https://doi.org/10.1016/j.apmr.2004.05.004

[15] Jacobson, G.P. and Newman, C.W. (1990) The Development of the Dizziness Handicap Inventory. Archives of Otolaryngology_Head and Neck Surgery, 116, 424427. https://doi.org/10.1001/archotol.1990.01870040046011

[16] Whitney, S.L., Hudak, M.T. and Marchetti, G.F. (1999) The Activities-Specific Balance Confidence Scale and the Dizziness Handicap Inventory: A Comparison. Journal of Vestibular Research, 9, 253-259.

[17] Fielder, H., Denholm, S.W., Lyons, R.A. and Fielder, C.P. (1996) Measurement of Health Status in Patients with Vertigo. Clinical Otolaryngology and Allied Sciences, 21, 124-126. https://doi.org/10.1111/j.1365-2273.1996.tb01314.x

[18] Whitney, S., Wrisley, D. and Furman, J. (2003) Concurrent Validity of the Berg Balance Scale and the Dynamic Gait Index in People with Vestibular Dysfunction. Physiotherapy Research International, 8, 178-186. https://doi.org/10.1002/pri.288

[19] Hall, C.D. and Herdman, S.J. (2006) Reliability of Clinical Measures Used to Assess Patients with Peripheral Vestibular Disorders. Journal of Neurologic Physical Therapy, 30, 74-81. https://doi.org/10.1097/01.NPT.0000282571.55673.ed

[20] Wrisley, D.M., Walker, M.L., Echternach, J.L. and Strasnick, B. (2003) Reliability of the Dynamic Gait Index in People with Vestibular Disorders. Archives of Physical Medicine and Rehabilitation, 84, 1528-1533. https://doi.org/10.1016/S0003-9993(03)00274-0

[21] Cattaneo, D., Regola, A. and Meotti, M. (2006) Validity of Six Balance Disorders Scales in Persons with Multiple Sclerosis. Disability and Rehabilitation, 28, 789-795. https://doi.org/10.1080/09638280500404289

[22] Herdman, S.J., Hall, C.D., Schubert, M.C., Das, V.E. and Tusa, R.J. (2007) Recovery of Dynamic Visual Acuity in Bilateral Vestibular Hypofunction. Archives of Otolaryngology-Head and Neck Surgery, 133, 383-389. https://doi.org/10.1001/archotol.133.4.383

[23] Franchignoni, F., Tesio, L., Martino, M.T. and Ricupero, C. (1998) Reliability of Four Simple, Quantitative Tests of Balance and Mobility in Healthy Elderly Females. Aging Clinical and Experimental Research, 10, 26-31. https://doi.org/10.1007/bf03339630

[24] Karapolat, H., Eyigor, S., et al. (2010) Reliability, Validity, and Sensitivity to Change of Turkish Activities-Specific Balance Confidence Scale in Patients with Unilateral Peripheral Vestibular Disease. International Journal of Rehabilitation Research, 33, 12-18. https://doi.org/10.1097/MRR.0b013e32832c0d72

[25] Binkley, J.M., Stratford, P.W., et al. (1999) The Lower Extremity Functional Scale 
(LEFS): Scale Development, Measurement Properties, and Clinical Application. Physical Therapy, 79, 371-383.

[26] Han, B.I., Song, H.S. and Kim, J.S. (2011) Vestibular Rehabilitation Therapy: Review of Indications, Mechanisms, and Key Exercises. Journal of Clinical Neurology, 7, 184-196. https://doi.org/10.3988/jcn.2011.7.4.184

[27] Mahler, D.A., Rosiello, R.A., Harver, A., et al. (1987) Comparison of Clinical Dyspnea Ratings and Psychophysical Measurements of Respiratory Sensation in Obstructive Airway Disease. The American Review of Respiratory Disease, 135, 1229 1233. https://doi.org/10.1164/arrd.1987.135.6.1229

[28] Prost, E. and Abbott, C. University of Missouri, School of Health Professions, Department of Physical Therapy. Modified Borg Rating Scale for Dizziness.

http://geriatrictoolkit.missouri.edu/vest/Borg-dizzy.pdf

[29] Kenny, O., Smyth, T.J., Hewage, C.M. and Brunton, N.P. (2014) Antioxidant Properties and Quantitative UPLC-MS/MS Analysis of Phenolic Compounds in Dandelion (Taraxacum officinale) Root Extracts. Free Radicals and Antioxidants, 4, 55-61. https://doi.org/10.5530/fra.2014.1.9

[30] Choi, U., Lee, O., Yim, J.H., et al. (2010) Hypolipidemic and Antioxidant Effects of Dandelion (Taraxacum officinale) Root and Leaf on Cholesterol-Fed Rabbits. International Journal of Molecular Sciences, 11, 67-78. https://doi.org/10.3390/ijms11010067

[31] Cohen, H., Blatchly, C.A. and Gombash, L.L. (1993) A Study of the Clinical Test of Sensory Interaction and Balance. Physical Therapy, 73, 346-351. https://doi.org/10.1093/ptj/73.6.346

[32] Hall, C.D., Herdman, S.J., Whitney, S.L., et al. (2016) Vestibular Rehabilitation for Peripheral Vestibular Hypofunction: An Evidence-Based Clinical Practice Guideline: From the American Physical Therapy Association Neurology Section. Journal of Neurologic Physical Therapy, 40, 124-155. https://doi.org/10.1097/NPT.0000000000000120

\section{Scientific Research Publishing}

Submit or recommend next manuscript to SCIRP and we will provide best service for you:

Accepting pre-submission inquiries through Email, Facebook, LinkedIn, Twitter, etc. A wide selection of journals (inclusive of 9 subjects, more than 200 journals)

Providing 24-hour high-quality service

User-friendly online submission system

Fair and swift peer-review system

Efficient typesetting and proofreading procedure

Display of the result of downloads and visits, as well as the number of cited articles

Maximum dissemination of your research work

Submit your manuscript at: http://papersubmission.scirp.org/

Or contact ijcm@scirp.org 